\title{
Researching Values in Mathematical Literacy: Trials and Impediments
}

\author{
Sheena Rughubar-Reddy (PhD) \\ University of Cape Town \\ Email: Sheena.Rughubar-Reddy@uct.ac.za
}

Doi:10.5901/mjss.2014.v5n23p1413

\begin{abstract}
This paper is part of a qualitative study that was conducted with Grade 10 students in three schools in Cape Town, South Africa, exploring the possible integration of values into mathematical literacy classrooms in mainstream secondary schools. Although values lie at the heart of every learning area, they are seldom explicitly expressed in the Mathematics or Mathematical Literacy classrooms. Curriculum 2005 requires educators to instil in learners knowledge, skills and values. The Critical Outcomes require learners to be able to work effectively as a team, organization or a community, while the Developmental Outcomes seek to produce responsible and sensitive citizens. Vital to this development, are the values that give meaning to the individual's spiritual and intellectual journey. This paper outlines the methodological difficulties encountered in researching the values that learners extract from their Mathematical Literacy lessons. A crucial issue that emerged was the reduced involvement of the teachers from the equation as they form an integral part of any lesson. Another challenge was finding an appropriate and shared vocabulary to discuss the types of values. I reflect on the differences in culture and personal value systems that have emerged, despite the fact that these were all schools in Cape Town.
\end{abstract}

Keywords: values; values education; mathematical literacy; shared vocabulary

\section{Introduction}

Over the years values education has been a contentious issue in many countries around the world. Experts agree on the vital role schools ought to play in fostering and developing values in learners and the moulding of their character (Rughubar-Reddy, 2013). It must be remembered that the majority of South Africans were victims of apartheid; an era that attempted to curtail critical and creative thinking amongst sectors of the population. This pervasive and malicious form of governance was very evident in education (King \& Van den Berg, 1991). As a result, there is concern that the transmission of values may result in moralizing, indoctrination and "authoritarian forms of imposition" (Morrow 2002:21).

The mathematics that is taught at schools is closely associated with the society in which it is taught (Seah \& Bishop, 2002). While school mathematics has played a vital role in preparing youth around the world to face the various economic, technological and social challenges and changes (Seah \& Bishop, 1999), society is making greater demands on its citizens to be numerate and demands that learners become more engaged with school mathematics (Bishop, 2007). The introduction of mathematical literacy into South African classrooms further reinforces this engagement by students. The Organisation for Economic Corporation and Ddevelopment/Programme for International Student Assessment (OECD/PISA) defines mathematical literacy as:

\begin{abstract}
... an individual's capacity to identify and understand the role that mathematics plays in the world, to make wellfounded judgements and to use and engage with mathematics in ways that meet the needs of that individual's life as a constructive, concerned and reflective citizen. (2003:10)
\end{abstract}

In many countries the relationship between learning mathematics (or mathematical literacy as in the case of South Africa) and living a meaningful life in society has been made explicit in their mathematics curriculum statements. The National Curriculum Statement (Grades 10-12) for Mathematical Literacy (South African Department of Education, 2001: 4-5), states the following about education and values:

Values and morality give meaning to our individual and social relationships. They are the common currencies that help make life more meaningful....An education system does not exist to simply serve as a market.....It's primary purpose must be to enrich the individual.

Many mathematics educators find it difficult to think about values in relation to their educational repertoire because 
professional development support in terms of conceptualising and discussing values are deficient (Seah \& Bishop, 2002:1). The popular public image of mathematics is that of an objective, abstract, inhumane subject independent of any human activities and values (Ahmed, 2007; Bishop, FitzSimons, Seah \& Clarkson, 2001; Goguen, 2007 \& Wong, 2005). The role of mathematics and mathematical literacy is not only to inculcate conceptual understanding and technical skills within the subject itself, but it is also concerned with the development of the learners' attitudes and values (Wilson, 1986). Ernest (1991) maintains that every mathematics curriculum implies certain values and ideologies and whether overt or covert, values play a significant role in both the choice of mathematical problems, methods of solution and the notations and concepts that are constructed in the process. According to Leu \& Wu (2004) values are implied in mathematics, mathematics curriculum and mathematics teaching. I maintain that values are also implied in mathematical literacy. Brooks and Kahn (1992:24) state that "teachers not only have values, they smuggle them into their classrooms every day". On the same note I would like to suggest that learners also smuggle their values into their classrooms as they carry the baggage of their various ethnic, class and gender identities. It is more difficult to conceptualise, identify and discuss values in mathematics, mathematical literacy and mathematics education than to talk about values in society.

Alan Bishop and associates (1999:1) define values in mathematics education as "the deep affective qualities which education aims to foster through the school subject of mathematics". In the South African context, this definition may be further extended to include the school subject of mathematical literacy. Seah \& Bishop $(1999,2001)$ suggest that values held by mathematics educators represent their internalization and 'cognitisation' of affective variables (such as beliefs and attitudes) in the context of the culture of one's community. The nature of mathematics and one's experience in the mathematics and mathematical literacy classrooms facilitate the inculcation of these values. The values equip the learner and (or) teacher with a pair of cognitive and affective lenses that shape and modify his or her perception and interpretation of the world. Hence in my view an understanding of values will lead to better teaching and learning in the mathematical literacy classrooms.

Since the South African Constitution and Children's Act in South Africa place a great degree of importance on the rights of children, I chose to focus on values and the learner. As one of the concerns of education is nation-building, a study was conducted to investigate how learners in secondary schools in Cape Town, South Africa understand, identify and implement values inherent in the mathematical literacy curriculum and lessons. I set out to answer the following questions: (i) what are the values inherent in the lathematical literacy lessons? (ii) how do these values manifest in the lessons? (iii) are learners able to 'distil' values from the content of the lesson? and (iv) do teachers' integrate values into the mathematical literacy lessons? This article outlines the challenges encountered in researching values inherent in the mathematical literacy classroom.

\section{Researching Values}

A challenge with researching values is to ensure that the research strategies employed would aid me in gaining some understanding into how learners perceived values in their mathematical literacy lessons. This section sketches the methodology that evolved to complete the task.

Two stages of sampling was necessary to facilitate this study; first the choice of schools and then the selection of learners who would participate in the focus group discussions. Three state schools in Cape Town, South Africa were chosen based on the criteria that they offered mathematical literacy to their Grade 10 learners and the teachers had undergone formal training in teaching mathematical literacy. The selection criteria also considered the social, political and cultural environments in which teaching and learning took place. Learners from the three classes (41 males and 56 females) were invited to participate in the study with five learners from each class volunteering to keep a journal and participate in focus group interviews. The following data collection methods were utilised in this study: document analysis, individual and focus group interviews, video recordings and classroom observation.

Document analysis was the initial step taken in an attempt to clarify the question of 'what are the values inherent in the mathematical literacy lessons?' The documents that I examined were related to values education and mathematical literacy at national (policy) and school (implementation) level. The purpose of the analysis was to determine the explicit and implicit aims and content of teaching and learning in the mathematical literacy classrooms. The data collected was to form the foundation for analysis at varying levels. Firstly I reviewed policy documents such as the South African Constitution, policy documents on education and curriculum statements. These documents were to aid my understanding of the state's views, aims and objectives with regard to values education. The information derived from these documents was used later to make comparisons with actual classroom practice. This was followed by a review of material that may be construed as implementation documents. These included the course syllabus, hand-outs given to teachers at workshops, resources used by the teachers, textbooks and worksheets used by the learners in mathematical literacy. In 
order to appreciate how the values manifest themselves in the mathematical literacy lessons, I carried out further analysis of the classroom materials. A review (restricted to the content of lessons that were to be observed at the three schools) of two textbooks, learner worksheets, assignments, tests and examination papers was undertaken. The analysis focused on mathematical content, mathematical literacy competencies, levels of Bloom's taxonomy, evidence of values (either explicit or implicit in the context or the content and the value itself. (Refer to Rughubar-Reddy, S. (in press). A framework for the analysis of values through a mathematical literacy lens, for greater detail on how the framework was developed). Table 1 provides a summary of the framework that evolved.

Table 1. Summary of Framework

\begin{tabular}{|lllll|}
\hline Content & Competencies & $\begin{array}{l}\text { Bloom's } \\
\text { Taxonomy }\end{array}$ & Evidence of Values & Value \\
\hline Compound growth \& Finance & Comparing numbers & Remembering & Explicit in either context or content & Love \\
Measurement & Critical thinking ability & Understanding & Implicit in either context or content & Truth \\
Numbers \& calculations & Data representation & Applying & Explicit in both context or content & Right Conduct \\
Patterns, relationships \& & Reading data from texts, & Analysing & Implicit in both context or content & Peace \\
representations & charts \& tables & Evaluating & Value absent from context and & Non-violence \\
Representation of statistical & Procedural competencies & Creating & content & \\
data & Writing proficiency & & & \\
\hline
\end{tabular}

Source: Adapted from Mhakure et al. (2013, p.395)

To further elucidate the question of how values manifest themselves in mathematical literacy lessons and gain some insight into whether teachers integrate values into their mathematical literacy lessons, I observed the lessons of the three teachers over a period of three months. Each school was visited in blocks of two weeks; hence there was a break between the two sets of visits. The aim of the classroom observations was to ascertain how both teachers and learners comprehend values and (or) values education in the mathematical literacy curriculum. Teachers were provided with a list of 150 values categorized under the headings: love, truth, right conduct, peace and non-violence. When planning each lesson teachers were asked to identify values that may arise during the course of the lesson. In this way teachers would be more reflective of their lessons. They were not required to inform me of the value(s) prior to the lesson. I did not want the teachers to detract from the mathematical content and competencies of the lesson. Interviews with the teachers, which followed the lessons, were unstructured and informal in nature and usually stemmed from my observations during the lesson. During these discussions the teachers would inform me of the value(s) that they had nominated and also reflect on whether they had integrated them into their lessons. These interviews provided some very significant data on the teachers' perceptions and views regarding values education and its integration into the mathematical literacy lessons.

In addition to allowing me to collect information from various learners in a single sitting, the focus group interviews also afforded me the opportunity to clarify issues and observe the twenty participants. In these post observation interviews I was interested in determining how the learners understand, identify and implement the values inherent in the mathematical literacy lessons and whether they were able to 'distil' values from the content of the lesson. The learners had to choose from a list (identical to that given to their teachers) those values that they felt had emerged during each of their mathematical literacy lessons. These values may be inherent in the content and/or context of the mathematical literacy curriculum or in the general classroom environment. Learners had to support their choice of value with an example from the lesson. To this end, they viewed video footage of each of the lessons that I had observed in their respective classrooms. These video recordings also served to help the learners remember and elaborate on incidents in the classroom that were associated with values. As the researcher I had also noted points in the lesson where values where illustrated (or missed opportunities for illustrating values had occurred). The aim of these focus group meetings also afforded the learners and me to come to an agreement on particular instances of when, where and how values education had occurred in a lesson.

I wanted to find out what guided the learners in their thinking on values. To help the process questions such as 'why did you choose that value?' or 'explain what you mean by that' were often posed to the learners. I also wanted to investigate how, if at all, the learners implemented these values in their classroom, within the school terrain and outside of school. The discussions were designed to ascertain from the learners how they would respond to situations in the real world. 


\section{Findings and Discussion}

This paper set out to sketch the methodological difficulties encountered in researching the values that learners extract from their Mathematical Literacy lessons. A reflection on the discussions held with both teachers and learners together an analysis of my notes on the research process gave rise crucial issues that need to be considered when researching values.

\subsection{Greater teacher involvement}

The teacher and learner constitute integrated elements in the classroom. Hence any attempt to research how learners' perceive values in a lesson requires the researcher to have a sense of the value(s) the teacher wishes to promote. Despite the fact that there were deliberations with the teachers post lesson observation, there was no certainty that during their lesson preparation the teachers had considered values as I had not asked for the values identified. Furthermore, there were unplanned opportunities during the lesson that the teacher may have used to make values explicit. Perhaps it is crucial that during the post lesson observations the teachers also viewed the video footage of each of their lessons to encourage recall of critical points. These video clips would have reinforced my comments about observations made about the lessons and also assisted the teachers confirm whether they had integrated the nominated values into their lessons. Moreover, it would have afforded the opportunity to stimulate the teachers' thoughts concerning the opportunities in the lessons that they may have overlooked for illustrating values.

Although the post-lesson interviews provided some very substantial data on the teachers' insights and opinions concerning values education and its integration into the mathematical literacy lessons, on reflection I think that the inclusion of the teachers in some of the focus group meetings may have provided a better synergy between teacher and learner perceptions and understanding of the values. Both teachers and learners would have benefitted from the observations made by each other.

\subsection{Issue of language}

The issue of language can become problematic when researching values as it is sometimes imprecise. Janet Powney (1996) contends that it is difficult to make concerns and issues explicit in a field when the language is imprecise. Language is a vital element in both understanding issues and expressing views. This study required of both teachers and learners the ability to make explicit through language the values implicit in the mathematical literacy lessons. On reflection I am of the opinion that it is more a lack of a 'shared vocabulary' (Clarkson, Bishop, FitzSimons \& Seah, 2000) than imprecise language which resulted in difficulty with discussing the values I was focusing on. In South African classrooms the issue of language is compounded by the diverse language backgrounds of the learners (there are eleven official languages in the country). For many of these learners English is not their first language hence one cannot be confident that certain words capture the desired shared meaning. Terminology can on occasion be broad hence there were times as the researcher I found difficulty in comprehending what the respondents meant and vice versa. Therefore, there were instances when I had to provide examples in the group interviews and discussions to ensure that the teachers and learners understood what was required of them. For the majority of South Africans there are certain words that have a negative association with the apartheid regime. Hence, there were times when we struggled to find an appropriate way to express these terms to convey a positive connotation. For example, the schedule of values lists 'discrimination' as a positive entity implying the ability to differentiate between good and bad. However, for many South Africans the word 'discrimination' conjures negative sentiments of being discriminated against; a product of the legacy of apartheid.

Learners confirmed that they had some command of a moral vocabulary as they were able to provide evidence for choosing the value they had identified. However, it became apparent to me that the learners repeatedly chose the same values suggesting that they have a limited moral vocabulary. Furthermore, they used a host of moral names to describe the same apparent value. They sometimes characterized a classroom episode as a particular value when what they really meant was the lack of the value. For example, learners classified the act of a teacher becoming angry when learners who did not understand mathematical concepts or procedures asked for help as an illustration of patience and tolerance when they actually meant a lack of patience and tolerance. I realised that failure to distinguish between different categories was the reason for this practice. The lack of moral vocabulary amongst learners may be ascribed to the absence of deliberate integration of values education by teachers.

It must be remembered that the teachers in the study had been students on an in-service course that I had taught; hence they were familiar with the concept of the integration of values into lessons. As a result there were times after my 
initial classroom observations when I had assumed that the teachers fully understood my questions and comments and did not elaborate or probe more fully a particular concept or classroom incident. Similarly, the converse, teachers presuming that I understood what was implied by their statements because I was present at the lesson, was also true. To alleviate any misconceptions and to fully comprehend the activities and occurrences the later lessons were thoroughly interrogated.

\subsection{Differing cultures and personal value systems}

Falkenberg (2006) claims that classroom teaching carries with it a moral dimension, irrespective of whether it is acknowledged while Jackson, Boostrom \& Hansen (1993) recognise that classroom teaching, independent of the subject content, influences the moral life in the classroom. Clarkson et al. (2000) who have made attempts to link teachers' beliefs to their teaching of mathematics suggest that values are beliefs in action. Beliefs are most often founded on an individual's cultural practices. Culture, ethnicity and gender wield a strong influence on values. South Africa has a culturally diverse population. During the apartheid era people lived in areas that were racially divided. Despite there being a shift to racially integrated areas in post-apartheid South Africa, there are still very many areas that are solely occupied by a single race or ethnic group. This determines the behaviour, norms and values evident in the given area. Though people move into areas that are more integrated, many retain their cultural/ethnic practices. Members of society become stereotyped according to ethnicity. Similarly learners and teachers bring with them into the classroom the norms and values associated with their culture and personal value systems. These may be alike or differ depending on the communities to which they belong. When envisioning the various scenarios during the development of the study it became evident that the situation may reach difficult proportions at times. For example, in certain African cultures it is a mark of disrespect to look an elder in the face. Hence a learner may avoid eye contact with the teacher as a gesture of respect. A teacher who does not share or know this culture may misinterpret this behaviour.

Associated with culture is the influence of South African politics on values. Many South Africans are still rooted in the past, despite the rainbow nation being two decades old. Local politics is keenly associated with religion and culture. The dominant religious and cultural beliefs of the area impact on the political philosophy as well. Since many of the political parties have a youth wing, the philosophy of the mother party is invariably adopted by the learners. The interviews confirmed that learner understanding of values is securely seated in their social, cultural and religious background and experiences and the learners draw on these backgrounds to make certain judgment calls. The communities in which the learners live determine their behaviour and value judgments. Sometimes learners needed to act in a manner that would ensure their survival. I observed that learners' understanding of values and their value judgments were resonant of their environment and circumstances.

Hence the diversity that manifests in South African classrooms presents the researcher who wishes to undertake a study on values with a plethora of challenges.

\section{Concluding Remarks}

Despite this paper highlighting the trials and impediments encountered when researching values, it also draws attention to the crucial role of methodology to the process. Although some approaches presented may provide insight into alleviating methodological problems, challenges such as the development of an appropriate and shared moral vocabulary still linger. The difficulties of researching against the grain of personal value systems and across differences in ethnicity, gender and cultural, political and religious beliefs have also been elucidated. Regardless of the myriad of challenges and constraints of undertaking studies in values, the possibilities for research in this area are numerous.

\section{References}

Ahmed, A. (2007). Some explorations into inhibitors and facilitators in learning mathematics in Gellert, U. \& Jablonka, E. (Eds).Mathematisation and Demathematisation. Social, Philosophical and Educational Ramifications. Sense Publishers. The Netherlands. (p141-160)

Bishop, A.J. (2007). Values in Mathematics and Science Education: An Empirical Investigation in Gellert. U. \& Jablonka, E. (Eds).Mathematisation and Demathematisation. Social, Philosophical and Educational Ramifications. The Netherlands: Sense Publishers. (p123-139)

Bishop, A. J., FitzSimons, G. E., Seah, W.T., \& Clarkson, P.C. (2001). Do teachers implement their intended values in mathematics classrooms? In M. v. d. Heuvel-Panhuizen (Ed.), Proceedings of the 25th Conference of the International Group for the Psychology of Mathematics Education (Vol. 2, pp. 169-176). Utrecht, The Netherlands: Freudenthal Institute. http://www. 
education.monash.edu.au/projects/vamp. (24/05/2008).

Brooks, B. D. \& Kahn, M. E. (1992). Value-added Education. The American School Board Journal 179(12): 24 - 27

Clarkson, P.C., Bishop, A.J., FitzSimons, G.E., \& Seah, W.T. (2000). Challenges and Constraints in Researching Values. In J. Bana \& A. Chapman (Eds.), Mathematics education beyond 2000: Proceedings of the twenty-third annual conference of the Mathematics Education Research Group of Australasia, held at Fremantle, Western Australia, 5-9 July, 2000. (Vol. 1, pp. 188-195). Perth, Australia: Mathematics Education Research Group of Australasia Incorporated. http://www.education.monash.edu.au/ projects/vamp. (24/05/2008).

Falkenberg, T. (2006). Moral education in the teaching of mathematics. In Novotna, J., Moraova, H., Kratka, M. \& Stehlikova, N. (Eds). Proceedings 30th Conference of the International Group for the Psychology of Mathematics Education, Vol. 3, pp. 49 - 56. Prague: PME.

Goguen, J.A. (2007). Reality and Human Values in Mathematics. http://scholar.google.co.za/scholar/RealityandHumanValuesin Mathematics.(8/09/2008).

Jackson, P. W., Boostrom, R.E. \& Hansen, D.T. (1993). The moral life of the Schools. San Franciso: Jossey-Bass.

King, M. and Van den Berg, O. (1991). Politics of Curriculum: Structures and Processes. Pietermaritburg : Centaur/IEB.

Leu, Y. C. \& Wu, C. J. (2004). The mathematics pedagogical values delivered by an elementary teacher in her mathematics instruction: attainment of higher education and achievement. In the Proceedings of the $28^{\text {th }}$ Conference of the International Group of the Psychology of Mathematics Education. (Vol. 3, pp. 225-232).

Morrow, W. (2002). Humanity in the Contemporary World in Asmal,K. \& James, W. (Eds). Spirit of the Nation. South Africa: New Africa Education.

Organisation for Economic Co-operation and Development (2003). The PISA 2003 Assessment Framework - mathematics, reading, science and problem solving: Knowledge and skills. Paris: OECD.

Powney, J. (1996). The Complexities of Researching Values. Observations No 8, Spring 1996. http://www.scre.ac.uk/spotlight/ spotlight56.html. (04/01/2007)

Rughubar-Reddy, S. (2013).Crouching learners, hidden values: Values in school mathematical literacy lessons. Unpublished doctoral thesis. University of the Western Cape, South Africa

Seah, W.T. \& Bishop, A.J. (1999). Realizing a mathematics education for nation-building in Southeast Asia. in Loo, S. P. (Ed.), Proceedings of the MERA-ERA Joint Conference 1999 (Vol. 3, pp. 1241-1249). Malaysia and Singapore: Malaysian Educational Research Association and Educational Research Association Singapore. http://www.education.monash.edu.au/projects/vamp. (24/05/2008).

Seah, W.T. \& Bishop, A.J. (2002). Values, Mathematics and Society: Making the Connections. In C. Vale \& J. Roumeliotis \& J. Horwood (Eds.), Valuing mathematics in society (pp. 105-113). Mathematical Association of Victoria: Brunswick, Australia. http://www.education.monash.edu.au/research/groups/smte/projects/vamp/mav2002.pdf

South African Department of National Education. (2001). National Curriculum Statement for Mathematical Literacy (Grades 10 - 12). Department of Education: Pretoria, South Africa.

Wilson, B. (1986). Values in Mathematics Education in Tomlinson, P. \& Quinton, M. (Eds). Values across the curriculum. London: The Falmer Press.

Wong, K.Y. (2005). Add Cultural Values to mathematics Instruction: A Singapore Initiative. http://ww1.math.nus.edu.sg/AMC/papersinvited/Wong-KF.pdf 